\title{
A IMPORTÂNCIA DO BRINCAR E DO BRINQUEDO PARA O DESENVOLVIMENTO INFANTIL
}

\author{
Daniele dos Santos Martins Vieira; Fabio Camargo Bandeira Villela \\ Universidade Estadual Paulista - UNESP, Graduação em Pedagogia. Presidente Prudente, SP. E-mail: \\ danielemartins1903@hotmail.com \\ Programa Núcleos de Ensino/PROGRAD/UNESP
}

\section{RESUMO}

O presente trabalho visa a abordar a importância do brincar para o desenvolvimento infantil. Tal prática ajuda a criança a externalizar o que sente, desperta criatividade, favorece asrelações sociais e auxilia no seu desenvolvimento corporal. Será abordadaa questão do brinquedo associada ao desenvolvimento da criança: a escolha do brinquedo possui um significado para cada fase do desenvolvimento, do nascimento até chegar à vida adulta. Por fim, será discutido o papel do adulto em relação ao brincar da criança, questões como: não interromper a brincadeira da criança, ensiná-la a brincar, não proibir e nem alterar as regras criadas pelas crianças.

Palavras-chave: Brincar, desenvolvimento, criança, brinquedo, conflito.

\section{THE IMPORTANCE OF PLAYING AND OF THE TOY IN INFANT DEVELOPMENT.}

\begin{abstract}
The present research investigates the importance of play in infant development. This practice helps children externalize what they are feeling, awakening creativity, promoting social relationships and assisting the development of their bodies. The question of toys associated with child development will be addressed: the choice of toy has significance at every stage of the development of the child, from birth until reaching adulthood. Finally, the role of the adult will be discussed in relation to the play of the children, including such matters as: not interrupting their games, teaching them to play, not altering or forbidding rules created by the children.
\end{abstract}

Keywords: Play, development, child, toy, conflict 


\section{INTRODUÇÃO}

A leitura da obra da Aberastury, "A criança e seus jogos", evidencia uma operação relativamente complexa de articular as etapas do desenvolvimento infantil segundo a psicanálise e os brinquedos específicos e adequados paracada idade.

Winnicott também tem muitas contribuições sobre o brincar e algumas delas servem como contraponto ou contribuição psicanalítica adicional às contribuições de Aberastury, seja porque auxiliam o esclarecimento das fases do desenvolvimento e aumentam o conhecimento em relação ao brincar, seja porque evidenciam a pluralidade temáticae a necessidade de estudo e debate no interior da compreensão psicanalítica sobre o brincar.

O brincar é fenômeno que desempenha diversas funções, como a de externalização de situações dolorosas, angustiantes, bem comopela sua contribuição ao desenvolvimento da capacidade criadora da criança, e à sua integração psíquica.

Uma série de temas são relevantes para a discussão do brincar para o desenvolvimento infantil, como a importância de determinados tipos de brinquedo em determinada idade da criança, bem como o usual significado desse nos diferentes momentos do desenvolvimento da criança, e também a maneira do adulto agir em relação ao brincar da criança, a questão de o adulto não interromper a brincadeira da criança, a quantidade de brinquedos que deve dispor à criança eque tipo de brinquedo dar para ela.

Este trabalho tem como finalidade discutir a importância do brincar e do brinquedo para o desenvolvimento infantil, com base nos estudos do livro da Arminda Aberastury "A criança e seus jogos", e em alguns contrapontos ou complementos a partir do livro "A criança e seu mundo" de Winnicott.

\section{METODOLOGIA}

A metodologia utilizada para a realização desse trabalho foi pesquisa bibliográfica, buscando abordar o tema do brinquedo a partir de Aberastury, mas incluindo contrapontos e complementos com base na psicanálise de Winnicott.

\section{RESULTADOS}

O motivo de as crianças brincarem

O brincar é muito importante para o desenvolvimento infantil, as crianças brincam não só por prazer, ou por que gostam, mas também para externalizar o que estão sentindo, seus conflitos eangústias. Como afirma Winnicott:

Conquanto seja fácil perceber que as crianças brincam por prazer, é muito mais difícil para as pessoas verem que as crianças brincam para dominar angústias, controlar ideias ou impulsos que conduzem à angustia se não forem dominadas. ( WINNICOTT, 1982, p.162)

O brincar para Winnicott vai além de externalizar o que está sentindo, ele afirma que no brincar a criança adquire experiência. $O$ autor explica que os adultos se desenvolvem com as experiências de vida, e o desenvolvimento infantil vem com influências do brincar.Segundo o autor:

A criança adquire experiência brincando. A brincadeira é uma parcela importante da sua vida. As experiências tanto externas como internas podem ser férteis para o adulto, mas para a criança essa riqueza encontrase principalmente na brincadeira e na fantasia. Tal como as personalidades dos adultos se desenvolvem através de suas experiências da vida, assim as 
das crianças evoluem por intermédio de suas próprias brincadeiras e das invenções de brincadeiras feitas por outras crianças e por adultos. (WINNICOTT, 1982, p. 163)

Considerando que o brincar permite oexternalizar dos sentimentos e também contribui para a aquisição deexperiência, tal prática desperta na criança sua capacidade criadora, ajuda nas suas relações emocionais, que lhe auxiliará no desenvolvimento de contatos sociais, e também ajuda nas funções corporais.

Aberastury, em sua obra, concentra-se na importância do brincar e do brinquedo para cada fase do desenvolvimento. Para a autora, o brinquedo tem centralmente uma função de elaboração de conflitos ou de situações penosas, podendo reproduzir simbolicamente situações prazerosas ou dolorosas:

O brinquedo possui muitas das características dos objetos, mas, pelo seu tamanho, pelo fato de que a criança exerce domínio sobre ele, pois o adulto outorga-lhe a qualidade de algo próprio e permitido, transforma-se no instrumento para o domínio de situações penosas, difíceis, traumáticas, que se engendram na relação com os objetos reais. Além disso, o brinquedo é substituível e permite que a criança repita, à vontade, situações prazenteiras e dolorosas que, entretanto, ela por si mesma não pode reproduzir no mundo real. (ABERASTURY, 1992, p. 14,15)

O brincar é uma prática fundamental na vida da criança e deve ser valorizado: toda criança deve ter o seu tempo para brincar.

\section{Desenvolvimento e brinquedos específicos}

Aberastury trata especialmente do brinquedo relacionado ao desenvolvimento, desde o nascimento até a vida adulta.

No nascimento da criança, o cuidado que a mãe oferece é a primeira expressão de amor, e, a partir desse momento, a criança pensa que a mãe lhe pertence, seu interesse é centrado na mãe, e, segundo a autora, essa condição típica da criança vai até o segundo terço do primeiro ano de vida. A ausência de contato da mãe com o bebê nos primeiros anos de vida pode causar distúrbios com a realidade e pode causar até doenças da pele, como a autora afirma: "A carência desta relação satisfatória acarreta distúrbios no contato com a realidade e predispõe a criança a doenças da pele." (ABERASTURY, 1992, p.24)

Entre o terceiro e quarto mês, a criança já conhece a mãe e a rejeita, brinca com o corpo dela e se torna o objeto de amor e ódio, em uma única pessoa.

Um ponto relevante no livro deAberatury é a antecipação da posição depressiva entre o terceiro e quarto mês, bem como o precoce envolvimento da criança com a figura de pai.Sua justificativa vem pela relação de amor e ódio da criança com a mãe, que desprenderia a criança de sua mãe e começaria, assim, uma relação com o pai: "Esta revelação de totalidade inicia um processo de desprendimento que conduzirá à procura do pai e do mundo circundante." (ABERASTURY, 1992, p.25)

A primeira brincadeira da criança é a de se esconder, abrir e fechar os olhos. Nessas atividades, ela consegue elaborar o sentimento de perda, auxilia o sentido de permanência do objeto, ajuda a aceitar seu distanciamento momentâneo da mãe.

Os sons também auxiliam as crianças a lidarem com o sentimento de perda, o som some e aparece, ela experimenta tal prática com seu corpo, o som chamado de balbucios. A autora recomenda como primeiro brinquedo para a criança o chocalho, pois ele produz o mesmo efeito dos balbucios: o som aparece e desaparece. 
Com o chocalho, a criança descobre que, quando bate em objetos, pode reproduzir sons. Ela tenta reproduzir sons que lhe assustam. A autora afirma que esse brinquedo é muito importante para a criança, poisessa experimenta, assim, o poder perder e recuperar o que ama (ABERASTURY, 1992, p. 32)

Já entre o quarto e o sexto mês, a criança procura lidar com o sentimento de perda dos pais de diversas formas, e, com as atividades lúdicas, ela consegue elaborar este tipo de sentimento:

Emite sons e brinca com eles. Paradoxalmente, ao encontrar a forma de elaborar suas angústias de perda, exige com urgência incontrolável a presença de seus verdadeiros objetos: os pais. (ABERASTURY, 1992, p33)

Para a autora, nãoé apenas na questão da alimentação que a criança quer a mãe, mas também para ter certeza de que não a perdeu, o brinquedo pode substituir a ausência dos pais por um determinado tempo, não sendo, entretanto, aconselhável aos pais se ausentarem por muito tempo.

Nessa fase, o menino nota a diferença entre os sexos e sua brincadeira ainda continua sobre a elaboração do sentimento de perda, mas, nesse caso, seria com objetos que se unem e se separam. Até o primeiro ano, as brincadeiras da criança se baseiam em jogos de perder e recuperar, encontrar e separar, ainda busca lidar com o sentimento de separação.

Na segunda metade do segundo ano, a criança descobre a forma de manifestação de amor dos adultos, a forma de entrar em alguém, unir e separar, brincando, assim, com objetos ocos que pode conter algo dentro, brinca com tudo que possa ser penetrável, os olhos e os ouvidos das pessoas the chamam a atenção, surgindo uma das primeiras experiências de exploração. Brincam com tudo que possam explorar como buraco, canos, fendas na parede, buraco da fechadura, lápis, tudo que ela encontra para unir e separar.

As diferenças de brincadeiras de meninos e meninas começam, segundo a autora, entre os oito e doze meses:

A menina prefere colocar objetos num lugar oco, e seus brinquedos repetirão essa experiência; o menino, ao contrário, escolhe os objetos com os quais possa penetrar. Este interesse não é exclusivo: sua condição bissexual lhes permite desfrutar também do brinquedo do outro sexo, mas, se a criança é normal, sua escolha torna- se bem clara já nesta época. (ABERASTURY, 1992, p. 38)

Nessa fase, surge também o interesse pelas suas fezes e urina, para ela é uma representação de sua capacidade criadora, mas, devido à proibição do adulto, ela encontra substitutos, como massinha, lama, água e areia.

Ao final do primeiro ano, evidencia-se também o interesse pelo tambor, que simboliza o ventre fecundo da mãe e, além disso, serve como uma forma de comunicação e um escape para suas tendências agressivas. A bola e o globo também entrarão nessa fase simbolizando o corpo da mãe e surge o forte desejo de ter um filho. Conforme a autora,

Ao final do primeiro ano o globo e, depois, a bola constituirão o centro de seu interesse. As fantasias de união vão dando origem ao forte desejo de ter um filho. O corpo de sua mãe e também o seu próprio estão simbolizados nas formas esféricas. A menina e o menino se identificam com a mãe, querem um filho dentro de seu corpo, imaginam-no e brincam com esse desejo. (ABERASTURY, 1992, p. 44) 
Aparece também nesse final do primeiro ano o interesse por bonecas e animais, que se transformam em seus filhos, simbolizando a aprendizagem da maternidade e da paternidade.

Aos dois anos, a criança passa a se interessar por brinquedos como tampas, frigideiras, pratos, talheres, para que, assim, possa alimentar ou privar seus supostos filhos. Interessam por recipientes, por derramar substância de um lugar para o outro, atividades referente ao controle dos esfíncteres. A respeito disso Aberastury afirma:

Esta atividade lúdica pode ser tomada como indício de que espera e necessita aprender a controlar os esfíncteres, isto é, a adquirir a capacidade de entregar à sua vontade os conteúdos do corpo. (ABERASTURY, 1992, p. 48)

Aos três anos, a criança também consegue externalizar suas angustias através do desenho, e o objeto central de seus desenhos é seu corpo, simbolizado pela casa.

Outro ponto interessante citado pela autora é sobre os jogos com bolinhas de gude, bilboquê, futebol. Para ela, essas atividades possuem um grande significado genital. Nesse mesmo contexto, discute o jogo de amarelinha, de que tanto a menina como meninobrincam e que significa vantagens e dificuldades, no caso, céu e inferno.

Os jogos como lutas, corridas, futebol, pegar e esconder, brinquedos com as mãos, ganham destaque entre os sete ou oito anos e vai até a puberdade. A autora afirma que esses tipos de jogos simbolizam a exploração e a procura, que já possuem conteúdos genitais muito evidentes.Percebem-se tendências evolutivas dos jogos para as crianças: deinício, começa com brincadeiras com o corpo; depois, com os brinquedos, e, na fase acima discutida, abandona esses objetos e volta para seu corpo e de seu par. Esse abandono dos brinquedos gera uma longa luta. Conforme Aberastury diz:

Desprender-se dos brinquedos exige da criança uma longa luta de desolação. Há adolescentes que guardam alguns brinquedos de sua infância quando há muito não mais os utilizam para brincar ${ }^{1}$. (ABERASTURY, 1992, p.84)

Aos dez ou doze anos, já começam a formar grupos separados por sexo, para que assim possam conhecer suas funções. E, com o passar do tempo, esses grupos começam se juntar, surgindo as relações amorosas, que substituem o brincar com os brinquedos. Já adolescente, abandona seu mundo lúdico, deixa, aos poucos, seu corpo de criança. As perdas na infância contribuirãopara tornar-se adulta, as experiências que obteve na infância conduzirão a uma nova etapa, a de terem um filho.

Papel do adulto em relação às brincadeiras das crianças

Tanto Winnicott como a Aberastury tratam do comportamento dos adultos em relação às brincadeiras das crianças.

Winnicott afirma que não podemos interromper a brincadeira da criança, pois ela ajuda a criança a lidar com angústia ou ansiedade:

Contudo, o resultado prático é importante, dado que, enquanto as crianças brincam por prazer, pode-se-lhes pedir que parem de brincar, ao passo que a brincadeira lida com esses sentimentos de angústia ou de ansiedade, não podendo desviar dela as crianças sem Ihes causarmos aflição, angústia real ou novas defesas contra a mesma (tais como masturbação ou a divagação). (WINNICOTT, 1982, p. $162-163$ )

\footnotetext{
${ }^{1}$ A convergência dessa afirmação de Aberastury com os objetos transicionais postulados por Winnicott não pode ser fruto do acaso, embora não hajaexpressa referência ao autor.
} 
O autor também diz que os adultos contribuem para o reconhecimento da brincadeira na vida da criança, o adulto tem o papel primordial para o ensino das brincadeiras tradicionais, mas não deve impedir ou mudar a iniciativa da criança, devendo deixá-la livre para lidar com seus conflitos e para despertar sua capacidade criadora.

Aberastury também contribui com o tema, afirmando que os adultos que fabricam os brinquedos das crianças podem não saber o que de fato é interessante para a criança. A autora lembra que os brinquedos devem ser resistentes: os inquebráveis facilitam a descarga de suas angústias, diminuindo o temor de suas tendências agressivas e de seu sentimento de culpa; os que se quebram com facilidade geram na criança um sentimento de angústia. $O$ brinquedo pode ser simples, assim a criança terá oportunidade de projetar suas fantasias e ajudam a elaborar situações traumáticas.

O adulto não deve proibir a criança de brincar com brinquedos considerados adequados para o outro sexo. Conforme Aberastury:

Os adultos projetam seus preconceitos sobre a diferença de sexos, não vêem com bons olhos este brinquedo para os meninos e o permitem às meninas. Esquecem-se de que eles também brincaram de ter filhos e de cuidá-los. (ABERASTURY, 1992, p.52)

Outro fato importante é a questão de o adulto dar muitos brinquedos para criança, com essa atitude, ela acaba se sentindo perdida, confusa, e não expressa o que está sentindo.

\section{DISCUSSÃO}

O presente trabalho discutiu a importância do brincar para o desenvolvimento infantil a partir da contribuição de dois autores da psicanálise, Aberastury e Winnicott. O brincar está relacionado a aspectos fundamentais do desenvolvimento emocional, como obtenção de prazer, elaboração de conflitos e angústias e expansão do eu e da capacidade criadora da criança.

O desenvolvimento emocional saudável é acompanhado por determinados brinquedos e brincadeiras que são típicos do momento do desenvolvimento por que passa a criança, bem como das situações emocionais que precisa enfrentar. Nesse sentido, são extremamente significativos para o mundo mental da criança e desempenham um papel fundamental de acompanhar e também de propiciar esse desenvolvimento emocional. Em razão disso, o brinquedo fornece dicas aos adultos do estágio pelo qual a criança está passando, bem como de determinados medos ou conflitos que possam estar presentes para ela.

Nesse sentido, cabe ao adulto propiciar condições favoráveis ao brincar para a criança, de modo a expandir o euda criança e ter um campo propício para seu desenvolvimento emocional. Não cabe, entretanto, buscar direcionar a brincadeira da criança e usar o brinquedo para moldá-la aos caprichos ou inclinações dos adultos. Sobre esse ponto, Aberastury é enfática ao postular que o adulto não deve proibir a criança de brincar com brinquedos considerados próprios por ele apenas para o outro sexo.

\section{CONCLUSÃO}

O brincar é uma peça primordial para o desenvolvimento da criança. O brincar ajuda a criança a externalizar o que sente, desperta sua capacidade criadora, ajuda em suas funções corporais, Ihe auxilia a estabelecer contatos sociais.

Existem escolhas de brinquedos adequados a cada fase do desenvolvimento infantil e juvenil e essas sequências de brinquedos favorecemaconstrução de sua personalidade rumo àvida adulta.

Também foi abordado o papel do adulto junto ao brincar da criança. 
Em relação aos dois autores abordados, enquanto Aberastury enfatiza o brincar como forma de elaboração de ansiedades e conflitos, Winnicott enfatiza o aspecto de expansão do eu e da criatividade na criança.

\section{REFERÊNCIAS}

ABERASTURY, A. A criança e seus jogos. 2. ed. Porto Alegre: Artmed, 1992.

WINNICOTT, D. W. A criança e o seu mundo. 6 ed. Rio de Janeiro: LTC- Livros Técnicos e Científicos Editora S.A., 1982. 